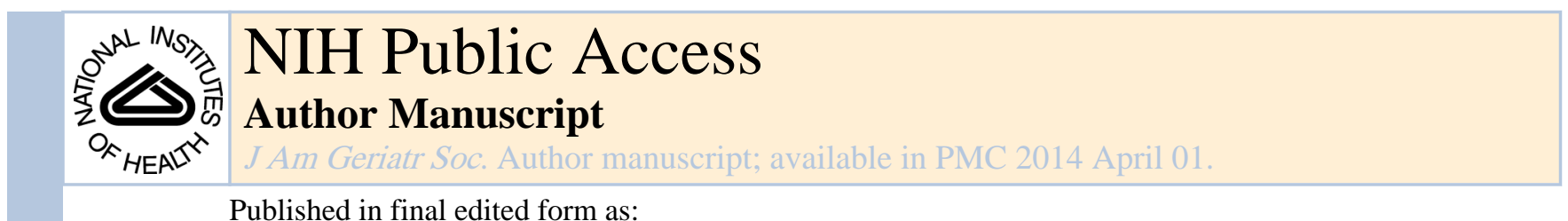

Published in final edited form as:

J Am Geriatr Soc. 2013 April ; 61(4): 667-668. doi:10.1111/jgs.12192.

\title{
Response Letter to Gazzaruso et al
}

\author{
Sei J. Lee, MD, MAS ${ }^{a, b}$, Celia K. Yau, MDc, and Catherine Eng, MD ${ }^{a, d}$ \\ aDivision of Geriatrics, University of California at San Francisco, San Francisco, California \\ bSan Francisco VA Research Enhancement Award Program, San Francisco, California \\ CUniversity of California at San Francisco and San Francisco VA PRIME Program, San Francisco, \\ California
}

dOn Lok Lifeways, San Francisco, California

\begin{abstract}
We'd like to thank Dr Gazzaruso and colleagues for their thought-provoking letter which suggests that our conclusion, that a HbA1c target of $8.0 \%$ may be lower than necessary for maintaining function in nursing home eligible elders, may be premature for 2 reasons. (1) First, they note that our study results run counter to previous studies where hyperglycemia was associated with disability. However, both of the cited studies were cross-sectional, raising the possibility that the observed association was due to reverse causation. Specifically, providers may have appropriately decreased the intensity of glycemic treatments for disabled patients, since these patients are often older with a higher burden of comorbidities putting them at higher risk for hypoglycemia. $(2,3)$ Thus, we believe our longitudinal study is an important advance from previous studies.
\end{abstract}

Corresponding author: Sei J. Lee, MD, MAS, 4150 Clement Street, Bldg 1, Rm 211A, San Francisco, CA 94121. Sei.lee@ ucsf.edu. Conflicts of Interest

\begin{tabular}{|l|l|l|l|l|l|l|l|l|l|}
\hline $\begin{array}{l}\text { Elements of } \\
\text { Financial/Personal } \\
\text { Conflicts }\end{array}$ & \multicolumn{2}{|l|}{ *Author 1 } & \multicolumn{2}{l|}{ Author 2 } & \multicolumn{2}{l|}{ Author 3 } & \multicolumn{2}{|c|}{ Etc. } \\
\hline & Yes & No & Yes & No & Yes & No & Yes & No \\
\hline Employment or Affiliation & & X & & X & & X & & \\
\hline Grants/Funds & & X & & X & & X & & \\
\hline Honoraria & & X & & X & & X & & \\
\hline Speaker Forum & & X & & X & & X & & \\
\hline Consultant & & X & & X & & X & & \\
\hline Stocks & & X & & X & & X & & \\
\hline Royalties & & X & & X & & X & & \\
\hline Expert Testimony & & X & & X & & X & & \\
\hline Board Member & & X & & X & & X & & \\
\hline Patents & & X & & X & & X & & \\
\hline Personal Relationship & & X & & X & & X & & \\
\hline
\end{tabular}

Author Contributions:

S. Lee: Concept, preparation, final revision of manuscript

C. Yau: Preparation of manuscript

C. Eng: Preparation of manuscript 
Second, Dr Gazzaruso and colleagues note that our studies occurred before the widespread use of dipeptidyl peptidase 4 (DPP-4) inhibitors and glucagon-like peptide 1 (GLP-1) agonists. We acknowledge that newer agents hold the promise of tighter glycemic control in older adults with less hypoglycemia. However, there is currently little data to suggest that these newer medications lead to improved patient outcomes such as decreased functional decline. Since these newer medications cost many times more than older medications and long-term safety is unknown, we believe that older medications should be tried first in the vast majority of older patients with diabetes.

For healthier elders with an extended life expectancy, we agree with Dr Gazzaruso that a reasonable $\mathrm{HbA} 1 \mathrm{c}$ target would be $7.0-7.5 \%$, as recommended by the International Association of Gerontology and Geriatrics (IAGG). (4) However, our study and conclusions focused on nursing home eligible elders for whom consensus statements recommend less stringent glycemic targets. The IAGG panel states that "in cases of functional dependence, care home residence... and other high dependency states, [HbAlc target] may need to be adjusted to reduce the risk of hypoglycemia and enhance patient safety." (4) Further, a recent American Diabetes Association and European Association for the Study of Diabetes consensus statement recommended that “...less stringent goals-e.g. 7.5-8.0\% or even slightly higher-are appropriate for patients with... a limited life expectancy [or] extensive comorbid conditions." (5) Thus, for elders with functional limitations and limited life expectancy, expert consensus statements appear to support our conclusion that a $\mathrm{HbA} 1 \mathrm{c}$ target of $8.0 \%$ may be lower than necessary to maintain function.

\section{Acknowledgments}

Dr. Lee's effort was supported by National Institutes of Health, National Center for Research Resources, OD, University of California at San Francisco, Clinical and Translational Science Institute Grant KL2 RR024130 and the Hellman Family Award for Early Career Faculty at University of California at San Francisco.

Sponsor's Role: The funding sources had no role in the design or conduct of the study, data management or analysis, or manuscript preparation

\section{REFERENCES}

1. Yau CK, Eng C, Cenzer IS, et al. Glycosylated hemoglobin and functional decline in communitydwelling nursing home-eligible elderly adults with diabetes mellitus. J Am Geriatr Soc. 2012 Jul; 60(7):1215-1221. [PubMed: 22702660]

2. Bossoni S, Mazziotti G, Gazzaruso C, et al. Relationship between instrumental activities of daily living and blood glucose control in elderly subjects with type 2 diabetes. Age Ageing. 2008 Mar; 37(2):222-225. [PubMed: 18033779]

3. Wu H, Flaherty J, Dong B, et al. Impact of Geriatric Conditions Versus Medical Diagnoses on ADL Disability Among Nonagenarians and Centenarians. J Aging Health. 2012 Dec; 24(8):1298-1319. [PubMed: 23006424]

4. Sinclair A, Morley JE, Rodriguez-Mañas L, et al. Diabetes mellitus in older people: position statement on behalf of the International Association of Gerontology and Geriatrics (IAGG), the European Diabetes Working Party for Older People (EDWPOP), and the International Task Force of Experts in Diabetes. J Am Med Dir Assoc. 2012 Jul; 13(6):497-502. [PubMed: 22748719]

5. Inzucchi SE, Bergenstal RM, Buse JB, et al. American Diabetes Association (ADA); European Association for the Study of Diabetes (EASD). Management of hyperglycemia in type 2 diabetes: a patient-centered approach: position statement of the American Diabetes Association (ADA) and the European Association for the Study of Diabetes (EASD). Diabetes Care. 2012 Jun; 35(6):13641379. [PubMed: 22517736] 